\title{
Pharmacokinetics and Clinical Pharmacology of Monoclonal Antibodies in Pediatric Patients
}

\author{
Zaid H. Temrikar ${ }^{1} \cdot$ Satyendra Suryawanshi ${ }^{2} \cdot$ Bernd Meibohm $^{1}$ (])
}

Published online: 13 February 2020

(c) The Author(s) 2020

\begin{abstract}
Monoclonal antibodies (mAbs) and their derivatives are increasingly used in pediatric pharmacotherapy, and the number of antibody-based drug products with approved pediatric indications is continuously growing. In most instances, pediatric use is being pursued after the efficacy and safety of novel antibody medications have been established in adult indications. The pediatric extrapolation exercise that is frequently used in this context to bridge efficacy and safety from adults to children is oftentimes challenged through uncertainties and knowledge gaps in how to reliably extrapolate pharmacokinetics and clinical pharmacology of mAbs to different pediatric age groups, and how to derive age-appropriate dosing regimens that strike a balance between precision dosing and practicability. The article highlights some of the pharmacokinetic and clinical pharmacology challenges with regard to therapeutic use of mAbs and antibody derivatives in children, including immunogenicity events. Although considering body size-based differences in drug disposition can account for many of the perceived and actual differences in the distribution and elimination of antibody-based therapeutics between children and adults, increasing evidence suggests potential or actual age-associated differences beyond size differences, especially for young pediatric patients such as newborns and infants. To overcome age-associated differences in antibody disposition, various different dosing approaches have been applied to ensure safe and efficacious antibody exposure for pediatric populations of different ages. The development of such dosing regimens and the associated pathway to pediatric indication approval is illustrated in more detail for two antibody-based biologics, the fusion protein abatacept and the mAb tocilizumab.
\end{abstract}

\section{Introduction}

For nearly 2 decades, biologics in general and monoclonal antibodies and antibody-derived products (collectively referred to in the following as mAbs) specifically have slowly grown to be a mainstay in the armamentarium of contemporary pharmacotherapy for numerous indications $[1,2]$. Similar to the majority of small-molecule drugs, most Abs were initially approved for adult indications, and have subsequently been pursued for juvenile, pediatric, and in some cases neonatal indications. Nevertheless, in some rare instances, pediatric indications were the initial target for mAb development programs, for example, palivizumab

Bernd Meibohm

bmeibohm@uthsc.edu

1 Department of Pharmaceutical Sciences, College of Pharmacy, University of Tennessee Health Science Center, 881 Madison Ave Room 435, Memphis, TN 38163, USA

2 Clinical Pharmacology and Pharmacometrics, Bristol-Myers Squibb, Princeton, NJ 08540, USA

\section{Key Points}

Monoclonal antibody-based medications are increasingly used in pediatric patient populations.

Especially in young pediatric patients such as newborns and infants, increasing emerging evidence suggests that potential differences in antibody pharmacokinetics cannot be sufficiently accounted for by body size-based dose adjustments alone.

Developing monoclonal antibodies for pediatric indications necessitates careful and prospective consideration of differences in disease etiology as well as age-specific antibody pharmacokinetics and pharmacodynamics to derive dosing algorithms that ensure safe and efficacious therapeutic use in the pediatric target population.

for the prevention of respiratory syncytial virus infection in newborns and infants [3].

Similarly to small-molecule drugs, the pharmacokinetics (PK) and pharmacokinetic/pharmacodynamic (PK/PD) 
relationships of biologics are expected to be affected by childhood maturational changes in drug disposition processes that are relevant for this specific set of compounds. In addition, size-specific adjustments for dosing are expected based on the generally accepted relationship between body size measures and determinants of systemic drug exposure, particularly clearance as a predictor of steady-state concentrations $[4,5]$.

In the first part of this article, we review the basic drug disposition processes for mAbs and the maturational processes that are known or expected to modulate these processes in a clinically relevant matter. In the second part, we review in detail the clinical pharmacology of two mAbs for pediatric indications and the challenges and peculiarities associated with their clinical development and use.

\section{Drug Disposition of mAbs in Pediatric Patients}

In order to comprehend the basic principles governing the drug disposition behavior of mAbs, it should be appreciated that most of the basic drug disposition processes of mAbsusually derived from chimeric, humanized, or human immunoglobulin $\mathrm{G}$ ( $\mathrm{IgG}$ ) molecules-are governed by their hydrophilic macromolecule nature (molecular weight $\sim 150 \mathrm{kDa}$ ), which is further complicated by their highly charged structure in the aqueous environment at physiologic $\mathrm{pH}$ and their general protein structure as a linear amino acid polymer chain. In addition, many $m A b s$ interact with a variety of generalized as well as specific receptor systems that may further affect their disposition. Age-associated changes in any of these processes and receptor systems as well as the physicochemical properties of the extracellular environment in pediatric patients of different ages may thus modulate the disposition behavior of mAbs. The major processes relevant for $\mathrm{mAb}$ disposition and their modulation in young pediatric patients as discussed in the following sections are summarized in Fig. 1.

\subsection{Distribution Processes}

As large, therapeutic proteins, mAbs are to a large degree confined to the vascular space, with substantially reduced extravascular concentrations relative to vascular [6]. Thus, the PK of mAbs can in most cases be described by the twocompartment distribution model, where the volume of distribution of the central compartment is equal to or slightly larger than the plasma volume, and the total volume of distribution is not more than two to three times the initial distribution volume [7]. The limited access to the interstitial space of peripheral tissues for $\mathrm{mAbs}$ is reflected by the endogenous $\mathrm{IgG}$ concentrations in the interstitial fluid of most tissues being only $10 \%$ of the concentration in plasma, although some tissues have more 'leaky' blood vessels and thus lower concentration differences. On the contrary, tight junctions between endothelial cells of brain capillaries lead to brain tissue concentrations for mAbs that are only $0.1-1 \%$ relative to plasma [8].

The extravasation of $m A b s$, i.e., the transfer from the plasma into the interstitial space, is largely driven by convective transport rather than diffusion processes as usually encountered for small-molecule drugs. Physiologic analyses of antibody disposition in mice suggest that $>98 \%$ of antibody enters tissue via convection [9]. Convection is determined by the flux of fluid from the vascular space into the interstitial space, which is driven by the blood-tissue hydrostatic and colloid osmotic pressure gradients, as well as by the number and size of paracellular pores in the vascular endothelium [10]. The rate of extravasation is tissue specific and dependent on capillary permeability. In addition, transcytosis through vascular endothelial cells, mediated via the neonatal $\mathrm{Fc}$ receptor $(\mathrm{FcRn})$, may be another important route of extravasation for $\mathrm{mAbs}$, especially in tissues where extravasation via convection is limited [6]. Lymphatic drainage of the interstitial space facilitates continuous fluid flux from the vascular space to the interstitial space and, via lymphatic vessels, ultimately back to the venous vascular system (subclavian vein).

Tissue distribution of mAbs is further hindered by the extracellular matrix that fills the interstitial space. It has a gel-like structure with a net negative charge and predominantly comprises glycosaminoglycans (e.g., hyaluronic acid) and structural proteins such as collagen. There is a mutual exclusion between IgG molecules and the structural proteins of the extracellular matrix [11].

Although initial assessments reported that the biodistribution of mAbs is likely not affected by developmental changes after differences in body size have been taken into account [3], more recent reports point out several processes that undergo age-associated changes and are relevant for $\mathrm{mAb}$ distribution [12]. Most strikingly, there is a well-known difference in the tissue water content of newborns and infants relative to that of older children and adults (Fig. 2) [13, 14]. Thus, the fraction of total body volume available for distribution would be expected to be higher in infants for hydrophilic macromolecules such as mAbs. In addition, the perfusion rate of tissues in newborns and infants is usually higher than that of the corresponding tissues in adults. Furthermore, infants have larger capillary beds and thus a larger capillary surface area per unit tissue volume as well as a larger proportion of 'leaky' organs and tissues (e.g., liver, kidneys, and spleen) with increased capillary permeability relative to their body size [15]. Taken together, extravasation would be expected to be faster and concentration differences between 


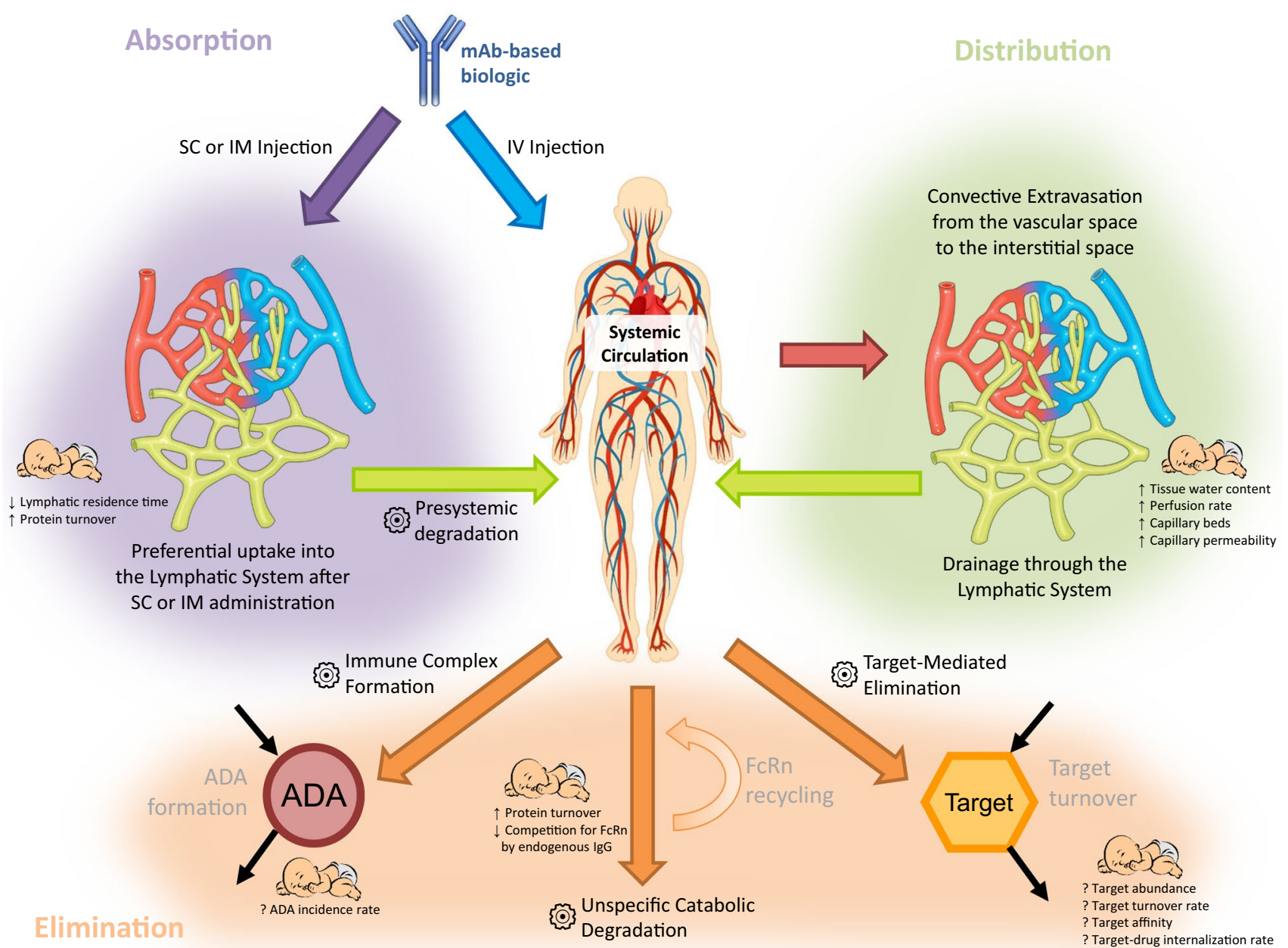

Fig. 1 Graphical summary of the major pharmacokinetic processes determining the disposition of antibody-based therapeutics and their modulation in young pediatric patients such as newborns and infants (indicated by the infant icon). The gear symbol $\tilde{\wp}$ indicates elimina-

vascular and extravascular spaces lower in newborns and infants compared to older children and adults.

Studies with labeled albumin and IgG molecules support this notion: although the transcapillary escape rate for $\mathrm{IgG}$ molecules is typically $40 \%$ lower than for albumin, the rate of extravasation for each of these proteins is approximately three times higher in neonates relative to adults [12, 16]. Whether this translates into differences in distribution parameters for plasma PK remains to be seen. A population PK-based analysis of a human mAb in five age groups of newborn, juvenile, and adult mice did not identify the necessity for age-related covariates after correction for size differences [17]. Further studies will need to assess whether the theoretically expected increase in the rate and extent of $\mathrm{mAb}$ distribution in young pediatric patients translates into clinically observable differences. tion processes. $A D A$ anti-drug antibody, $F c R n$ neonatal $F c$ receptor, Ig immunoglobulin, $I M$ intramuscular, $I V$ intravenous, $m A b$ monoclonal antibody, $S C$ subcutaneous

\subsection{Elimination Processes}

The elimination of mAbs from the body is largely facilitated by intracellular catabolism via lysosomal degradation after uptake into cells by either pinocytosis, an unspecific fluidphase endocytosis, or by a receptor-mediated endocytosis process [18]. Unlike small molecules, mAbs are too large to be filtered by the kidneys and are not eliminated in the urine, except in pathologic conditions [19].

Pinocytosis is a relatively unspecific fluid-phase endocytosis performed by endothelial cells lining the vascular system. Catabolic degradation of $\mathrm{IgG}$ in intracellular lysosomes following pinocytotic uptake is not limited to a specific organ, but occurs throughout the body, particularly in those organs and tissues rich in capillary beds with endothelial cells, such as the skin, muscle, and gastrointestinal tract [20]. 


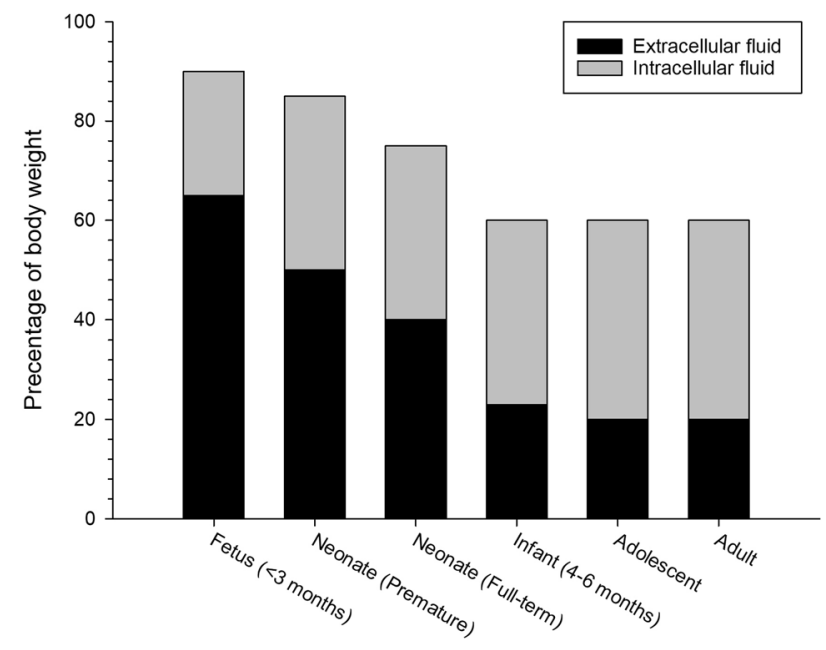

Fig. 2 Age-dependent changes in total body water, separated into intracellular and extracellular water content relative to total body weight. Based on data from [13]

Elimination through receptor-mediated endocytosis is facilitated through binding of the constant $(\mathrm{Fc})$ domain of an $\mathrm{IgG}$ molecule to $\mathrm{Fc}$-gamma receptors $(\mathrm{Fc} \gamma \mathrm{R})$ expressed on many immune cells, including monocytes, macrophages, and myeloid progenitor and dendritic cells [21]. Binding of $\mathrm{mAbs}$ to $\mathrm{Fc} \gamma \mathrm{R}$ triggers the endocytosis of the complex and subsequent intracellular degradation. Studies with FcyR knockout mice suggest that FcyR-mediated elimination likely plays only a minor role (if any) for most mAbs [22]. However, for those mAbs that form soluble immune complexes, mediate their pharmacologic activity through effector functions such as antibody-dependent cellular cytotoxicity (ADCC), and/or have increased binding affinity to Fc $\gamma \mathrm{R}$, receptor-mediated endocytosis via Fc $\gamma \mathrm{R}$ may constitute an additional elimination pathway that contributes to the overall elimination of the $\mathrm{mAb}$ [23].

Once taken up into lysosomes either by pinocytosis or receptor-mediated processes and the lysosome acidified, mAbs can interact with the FcRn via $\mathrm{pH}$-dependent binding to a specific binding site on the $\mathrm{Fc}$ domain of the $\mathrm{mAb}$ [24]. The FcRn interaction constitutes a salvage pathway for IgG molecules to escape intracellular lysosomal degradation. The formed $\mathrm{mAb}-\mathrm{FcRn}$ complex can recycle the $\mathrm{mAb}$ molecule back to the cell surface and release it from the binding, thereby avoiding its elimination. The interaction with the FcRn receptor thereby prolongs the elimination half-life of $\mathrm{IgG}$, with a more pronounced effect the stronger the $\mathrm{Fc}$ fragment of the antibody is bound to the receptor. $\mathrm{FcRn}$ recycling is the major reason that $\mathrm{IgG} 1, \mathrm{IgG} 2$, and IgG4 have a half-life in humans of 18-21 days, whereas the less strongly bound IgG3 has a half-life of only 7 days [7].

The efficiency of the FcRn recycling process, including binding affinity to $\mathrm{FcRn}$, protein expression of functional
FcRn, and endogenous IgG concentrations competing for $\mathrm{FcRn}$, as well as general age-associated differences in lysosomal protein turnover could be sources for differences in $\mathrm{mAb}$ elimination between children and adults after correction for size differences. Since children, including infants, are able to maintain the homeostasis of immunoglobulins, they also should be able to eliminate therapeutic mAbs through the endosomal clearance pathway [3]. Expression of FcRn is likely not substantially different between children and adults. Although a study investigating messenger RNA (mRNA) expression of the FcRn $\alpha$-chain of FcRn in rats suggested an age-associated increase in mRNA [25], more recent results on age-associated expression at the protein level in mice suggest no relevant differences in expression from newborn through juvenile animals to adults in skin and spleen tissues [17], which may be interpreted as more definitive due to the often limited mRNA-to-functional protein correlation for many endogenous proteins.

In addition, infants have substantially lower reference values for endogenous IgG subclasses compared to older children and adults once residual maternal immunoglobulin from placental transfer has been lost several weeks after birth. Those values slowly rise to adult levels over the first months and years of life (Fig. 3) [26]. With less competing endogenous IgG present, one could expect more efficient $\mathrm{FcRn}$ recycling and thus a reduced clearance of mAbs in this age group [27].

Protein turnover, i.e., catabolism in general, seems to be substantially higher in young pediatric patients compared to adults. For low-birth-weight infants, protein metabolism has been described as two to three times faster than in adults when normalized for kilograms of body weight [28]. Whether the effects of pediatric age on these processes related to $\mathrm{mAb}$ elimination cancel out or whether they actually achieve clinically detectable differences in mAb elimination remains to be determined in future studies.

Although some differences in the expression and activity of Fc $\gamma R$ have been reported in neonatal versus adult immune cells [29], the overall limited impact of Fc $\gamma \mathrm{R}$ on the elimination of most mAbs renders this potential source of age-associated differences only relevant for those few mAbs where this pathway may play a larger role.

\subsection{Target-Mediated Drug Disposition}

All therapeutically used mAbs are designed to specifically bind to a target structure, usually a soluble antigen or a membrane-standing receptor. Binding of a $\mathrm{mAb}$ to its target results in the formation of a mAb-target complex. For membrane-standing receptors, this complex can be internalized into the cell and can subsequently undergo lysosomal degradation [1]. Thus, binding to the target of a mAb can constitute an additional elimination pathway. This process 


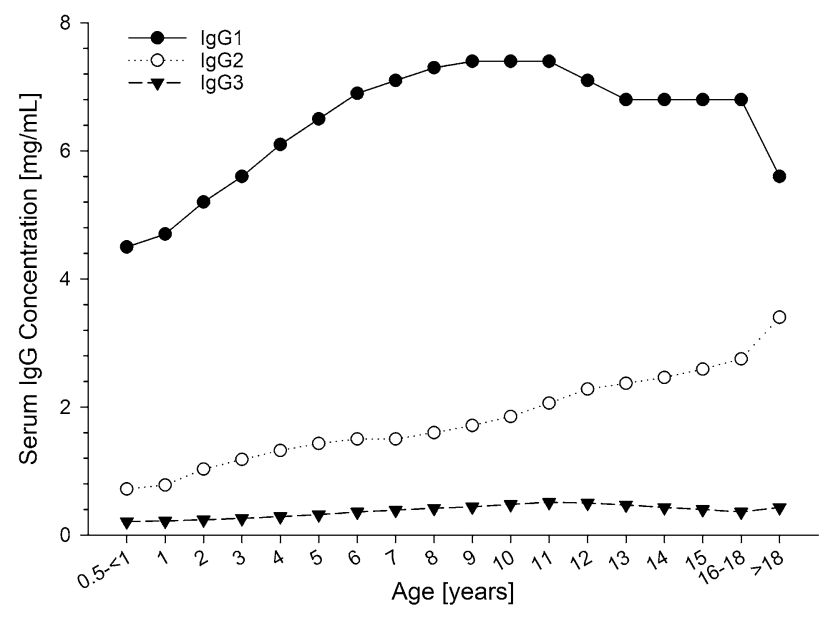

Fig. 3 Median serum IgG subclass concentrations in healthy subjects at different age. Based on data from [26]. Ig immunoglobulin

has been termed 'target-mediated drug disposition' (TMDD) [30]. Since mAbs usually have a very high binding affinity to their target, the TMDD-related clearance process can contribute to a major degree to the overall elimination of a $\mathrm{mAb}$, especially when molar mAb concentrations are small relative to the available target. The rate of elimination of a drug through TMDD is dependent on the expression and turnover kinetics of the target receptor (which is usually limited), the affinity of the $\mathrm{mAb}$ for the receptor, the dose of the $\mathrm{mAb}$, the rate of receptor-therapeutic protein internalization, and the rate of catabolism within the target cell. Since the number of target receptors is usually limited, elimination through TMDD can usually be saturated within therapeutic concentrations or, more specifically, at relatively low molar ratios between the drug and the target. As a consequence, mAbs that undergo TMDD exhibit dose-dependent, nonlinear PK behavior [6].

TMDD does not only occur for mAbs targeting membrane-standing receptors, but can also be seen for soluble targets if the formed $\mathrm{mAb}$-antigen complex between the $\mathrm{mAb}$ and antigen triggers the usual endogenous elimination processes for immune complexes [31]. Potential differences in the age-associated expression of $\mathrm{mAb}$ targets, their turnover kinetics, binding affinity, and internalization rates have so far not been reliably described, and would likely be tissue, indication, and target specific. Those potential differences, however, could be a source for additional deviations for the PK of mAbs in children relative to adults.

\subsection{Routes of Administration}

mAbs are not bioavailable after oral administration to any relevant extent. This is largely the consequence of their large size and high charge, which severely restrict their ability to transfer through biomembranes, as well as their limited stability towards gastrointestinal proteases [6]. Although the FcRn has been implicated in transcytosis processes and has been described to be expressed in pediatric and adult enterocytes, its function seems to be focused on transcytosis from the basolateral surface of the cell to the gut lumen to convey IgG-related mucosal immunity rather than $\mathrm{IgG}$ absorption processes [24]. Thus, parenteral administration pathways are used to deliver mAbs to adults and children. Intravenous (IV) infusion is the most common route of administration, followed by subcutaneous (SC) and intramuscular (IM) injection. SC injections using syringes or pen devices are now widely used for many mAbs due to their popularity with patients, allowing self-administration outside of healthcare settings. For young pediatric patients such as infants, however, IV and to a lesser degree IM administration is usually preferred. The preferential use of IM relative to SC administration in this patient population is based on the ease of injection into the muscles (vastus lateralis) of the thigh in young children [12].

After SC or IM administration, uptake of mAbs is facilitated by convective transport into the lymphatic system and only to a very minor degree by diffusion into blood capillaries [32]. Because the flow of lymph fluid in lymphatic vessels is substantially slower compared to the blood flow in capillary vessels $(\sim 0.2 \%$ of plasma flow rate) [33], the resulting absorption process of mAbs into the systemic circulation after SC or IM administration is also slow, with a corresponding slow increase in plasma concentration and delayed time of the maximum concentration $\left(T_{\max }\right)$, ranging for mAbs from 1.7 to 13.5 days, with frequent values of $T_{\max }$ around 6-8 days [34].

mAbs administered by the SC or IM route may undergo presystemic elimination, which can be attributed to a combination effect of soluble peptidase activity in the interstitial space, endocytosis and lysosomal degradation in endothelial cells lining the lymphatic vessels, as well as interaction with phagocytic immune cells in the lymph nodes. As a consequence, $\mathrm{mAb}$ bioavailability values after SC or IM injection range from 52 to $80 \%$ [7].

A variety of factors have been identified that affect the rate and extent of absorption after SC and IM administration [35]. This includes the site of injection, which determines the pressure gradients in the local interstitial space [36], but also body weight, gender, age, activity level, disease state, respiratory rate, and blood pressure [37]. As a consequence of all these factors, there is substantial variability in the rate and extent of absorption between different mAbs and between different individuals for the same $\mathrm{mAb}[1,38]$.

Based on the increased extracellular fluid volume in young pediatric patients compared to older children and adults, as well as the previously discussed higher perfusion rates that are assumed to be equally affected for plasma and 
lymph ( $\sim 2 \%$ of plasma flow rate), one would expect an increased absorption rate for $\mathrm{mAbs}$ in infants and young children. This seems to be confirmed by palivizumab IM administration in infants and adults, with a three times faster absorption rate in children [39]. The same study, however, reported no difference in the extent of bioavailability between the two age groups. The underlying degree of presystemic degradation as a main determinant of $\mathrm{mAb}$ bioavailability after SC or IM administration is thought to be a function of residence time in the lymphatic system and elimination rate during lymphatic transport. If the rate of absorption is increased in infants and young children, the elimination rate during lymphatic transport would also need to be increased to result in similar bioavailabilities [12]. Potential explanations for this could be a reduced efficiency of FcRn recycling or increased endosomal protein turnover in children relative to adults, as discussed earlier [28].

\subsection{Immunogenicity}

Immunogenicity is the ability of a substance to elicit an immune response. All mAbs as therapeutic proteins have the potential to trigger an immune reaction upon single or repeated administration [40]. In most instances, this immune reaction leads to the formation of endogenous anti-drug antibodies (ADA). The immunogenic potential of mAbs is related to a variety of factors, including the fraction of nonhuman sequence in the mAb molecule, the route of administration, and the dose and duration of therapy [41]. The observed incidence of ADA positivity in a study, however, may also be influenced by other factors such as sample handling, timing of sample collection, use of concomitant medications, and underlying disease. Thus, there is often substantial variability observed in ADA incidences for the same product in a particular disease population [42]. This makes it challenging to identify patterns and compare ADA occurrence and severity in different populations and draw reliable conclusions $[43,44]$.

Immunogenicity resulting in ADA formation is usually a polyclonal response, with multiple ADA species concurrently available and interindividual differences from patient to patient. The formed ADA can either be neutralizing antibodies or non-neutralizing antibodies. Neutralizing ADA obliterate the effect of the mAb by binding to complementarity determining regions, i.e., their antigen binding sites. The level of neutralization is often dependent on the titer of ADA. Non-neutralizing ADA do not interfere with the mAb's antigen binding capacity $[1,2]$.

Independent of whether ADA are neutralizing or nonneutralizing, ADA formation frequently has an effect on the PK and systemic exposure of the affected $\mathrm{mAb}$, although not all ADA result in a change in the mAb's PK behavior. If there is an effect on PK, it is usually a dramatic increase in the elimination of the affected $m A b$, resulting in a substantially reduced or no appreciable systemic exposure of the $\mathrm{mAb}$ [40]. The mechanistic basis for this increased clearance is the formation of circulating ADA-mAb immune complexes that are large enough to trigger uptake and lysosomal degradation by the reticuloendothelial system, mediated via binding of the $\mathrm{Fc}$ domain to $\mathrm{Fc} \gamma \mathrm{R}$, primarily on platelets, and subsequent internalization by circulating phagocytes. Thus, ADA-mAb complex formation is an additional clearance pathway for the affected $\mathrm{mAb}$ [6].

With over 1600 genes involved in innate and adaptive immune responses, the human immune system is extraordinarily complex [45]. The transcription of many of these genes changes with age, and the overall immune system undergoes dramatic developmental changes throughout childhood development [45, 46]. Age-related alterations that have been shown to cause changes in immune reactivity include, for example, maturation of regulatory $\mathrm{T}$ cells and other T-lymphocyte populations [47, 48] and generation of robust memory responses [49]. Although differences in immune reactivity may be expected between pediatric patients and adults based on the maturation of immune system functionality, the detection of these differences and assessment of their magnitude is complex, with considerable caveats. These are largely related to the fact that the assay technology used to quantify ADA formation relies on semi-quantitative assays, with the consequence that the assay results cannot be compared between different mAbs or even the same mAb when different assays are applied [44].

ADA formation is a well-recognized impediment to $\mathrm{mAb}$ based therapies in pediatric indications, such as juvenile idiopathic arthritis (JIA) [50]. The current literature suggests no significant difference in immunogenicity between adults and pediatric populations for most investigated mAbs, including etanercept, infliximab, and tocilizumab [3]. Nevertheless, a careful review considering the noted methodological limitations reported notably higher ADA incidence rates for adalimumab, abatacept, and daclizumab in children compared to the respective adult populations [3]. Whether these perceived differences in immunogenicity between children and adults are indeed based on differences in immunoreactivity between different age groups and whether these ultimately translate into actionable differences in the clinical pharmacology of these affected mAbs remains to be confirmed in more systematic and controlled future investigations.

\subsection{Extrapolation of Pediatric PK and PK/PD Relationships}

One of the challenges in pediatric drug development and applied pharmacotherapy is the lack of experimental data in pediatric populations that may inform initial dose selection. 
One frequently applied approach to overcome this limitation is the extrapolation of PK and exposure-response relationships from adults [5].

For mAbs, allometric scaling approaches have been shown to be relatively reliable for extrapolating PK parameters between different mammalian species despite wellknown species differences in endogenous proteins, as long as the disposition processes for the mAb are governed by unspecific proteolytic degradation pathways and do not include interaction with endogenous receptor systems. The reason is likely the similarity in how proteins, including $\mathrm{mAbs}$, are handled in different mammalian species. Once receptor-mediated processes are involved, however, species differences need to be considered [6]. Similarly, allometric scaling approaches are frequently also applied to extrapolate adult $\mathrm{mAb}$ PK data to pediatric populations. Again, this sizebased allometric approach usually works well until a lower age range is reached, for which immature and age-specific disposition processes require additional consideration, oftentimes in the age group below 6 months.

Development of $\mathrm{mAb}$ dosing regimens for pediatric patients may be facilitated by pediatric extrapolation if the exposure-response relationship can be established in the pediatric population [51]. This has, for example, been done for golimumab, where a model-based analysis of clinical endpoints in children (6-17 years) with ulcerative colitis indicated that the exposure-response relationship was similar between the pediatric group and adults. Thus, dosing regimen design in pediatric age groups was guided by exposure matching of golimumab plasma concentrations with the approved dose level in adults [52].

Pediatric extrapolation becomes more challenging if exposure-response relationships are not identical between children and adults, for example, if the childhood condition is distinctively different from the adult disease. In those instances, more clinical efficacy and exposure data may be necessary to inform pediatric dosing regimen design. Pharmacometric approaches such as systems pharmacology and physiologically based PK modeling are increasingly being used to bridge some of the associated uncertainties in pediatric dose extrapolation $[53,54]$.

\subsection{Pediatric Dosing Approaches}

In order to account for size- and maturation-related differences in dose requirements for different pediatric populations relative to adults, a variety of different dosing strategies have been applied for pediatric mAb indications [55]. These usually try to strike a balance between sufficient granularity to account for age- and size-related differences to ensure comparable systemic exposure and limited clinical complexity, in order to avoid overburdening healthcare providers and to limit dosing errors. Table 1 lists dosing approaches for mAbs that are Food and Drug Administration (FDA)approved in pediatric indications.

\subsubsection{Flat Dosing}

Flat dosing across different age groups would likely result in large exposure differences among children of different ages for the reasons outlined in the previous paragraphs. Thus, such an approach would only be acceptable for mAbs that are well tolerated and thus can be given at doses resulting in effective and safe plasma concentrations across the pediatric age spectrum or that have flat exposure-response relationships for both efficacy and safety.

\subsubsection{Body Weight-Based Dosing}

Body weight-based dosing remains the most frequently applied pediatric dosing strategy for mAbs. When the approved dosing covers a wide age range, weight-based dosing may not be optimal for all children due to the common nonlinearity of $\mathrm{mAb}$ clearance relative to body weight [7]. In order to address this shortcoming, several dosing approaches use more than one weight-based dose throughout the pediatric spectrum.

\subsubsection{Body Surface Area-Based Dosing}

Body surface area (BSA)-based dosing remains limited to a few mAbs, particularly in cancer indications. The major reasons seem to be the complexity of estimating BSA from height and weight, with its associated inaccuracies [3], the limited relationship between clearance and BSA for most mAbs [2], and the lack of a substantial advantage of this dosing strategy relative to the other discussed approaches. At the current time, only gemtuzumab ozogamicin uses BSAbased dosing in children.

\subsubsection{Allometrically Adjusted Dosing}

Allometrically adjusted dosing based on theoretical considerations $[4,5]$ as well as practical observations from population PK analyses [7] seems to be the most precise approach when clearance and volume of distribution scaling is performed with the classical allometric exponents of 0.75 and 1 , respectively, as long as no other maturation-related processes beyond body weight affect the mAb PK. While dose adjustments based on allometric equations seem attractive as they account for the nonlinearity in the weight versus clearance relationship, they remain impractical in clinical practice and are thus not applied for any of the mAbs approved for pediatric indications. 


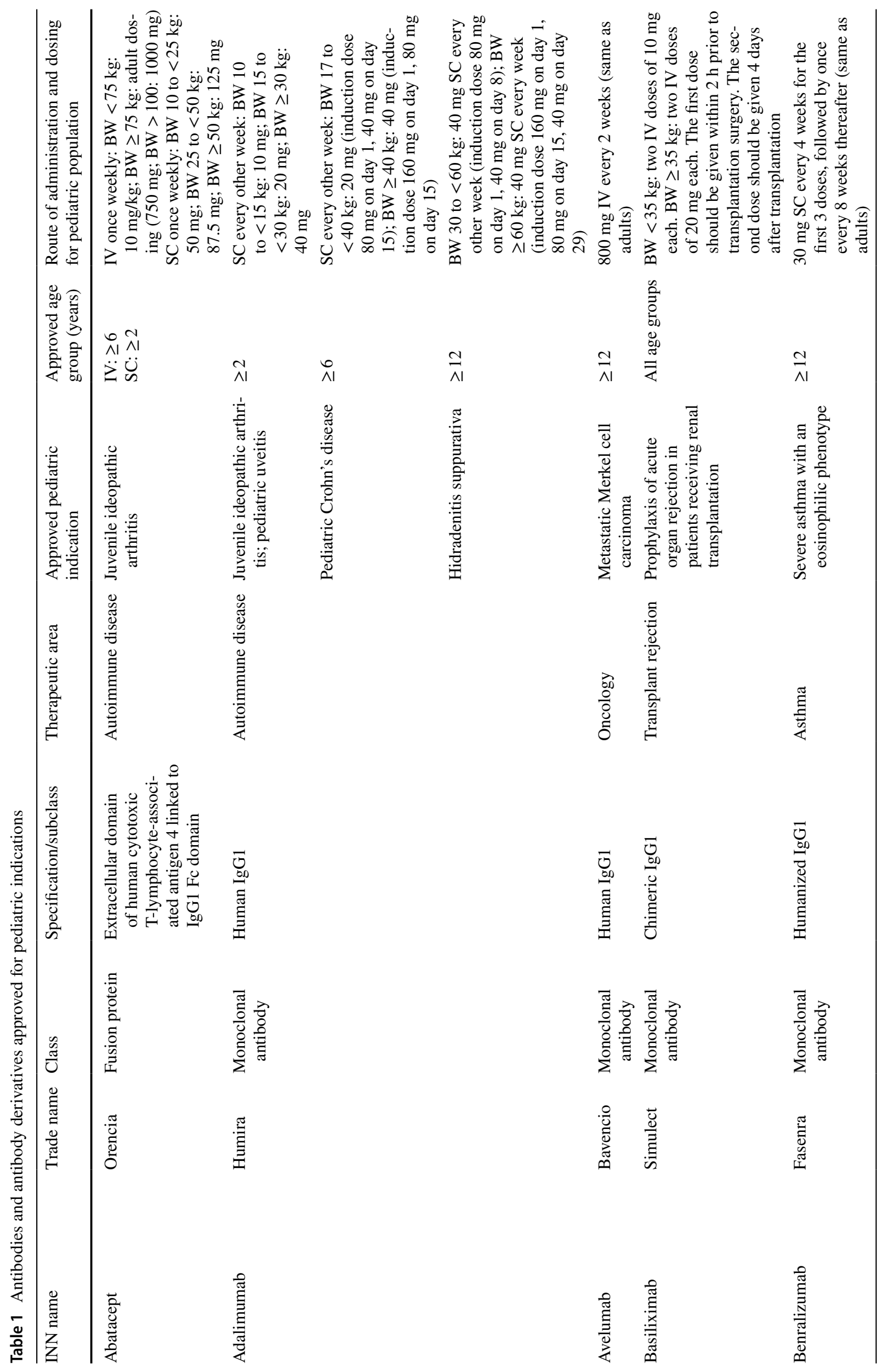




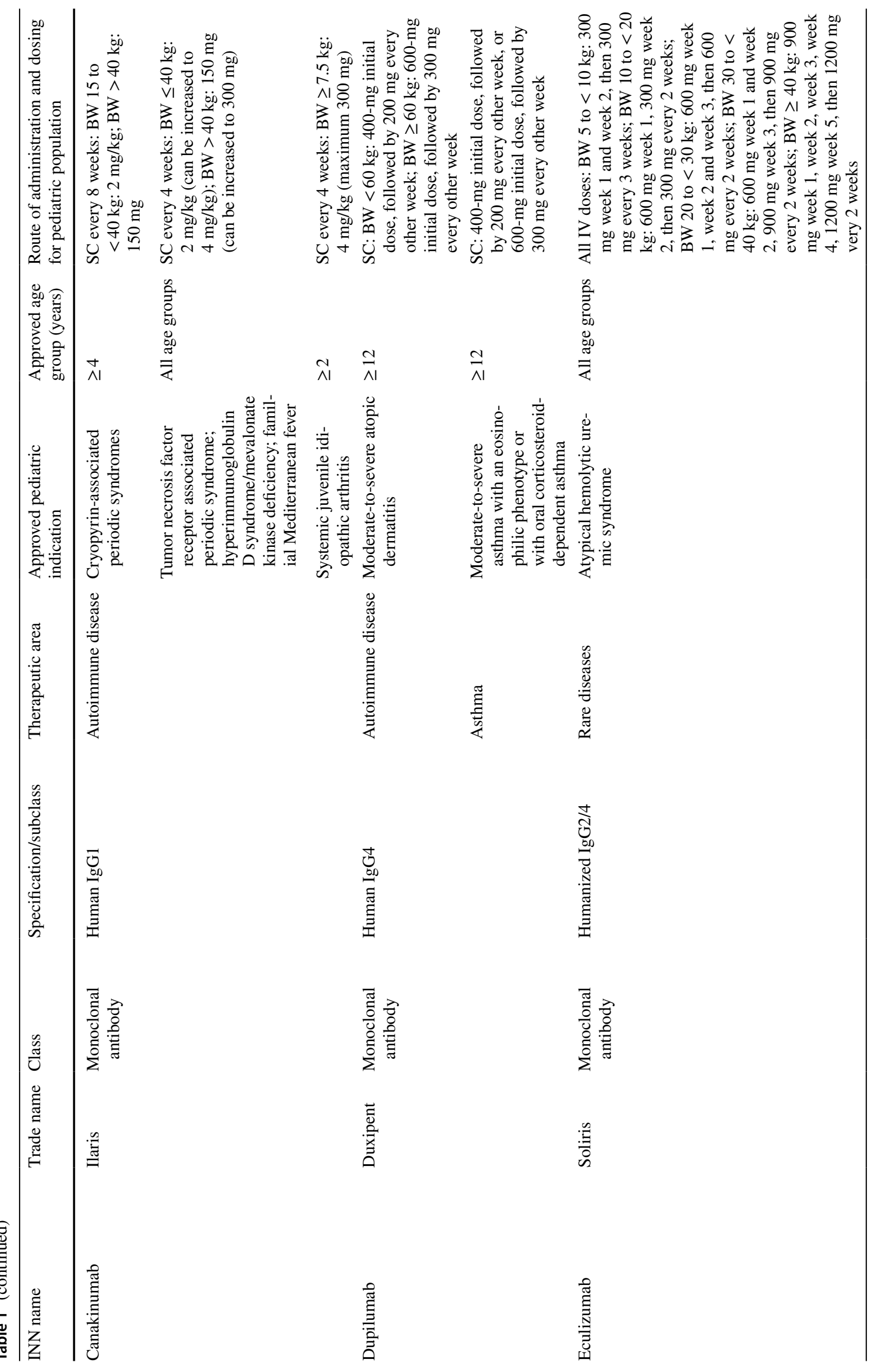




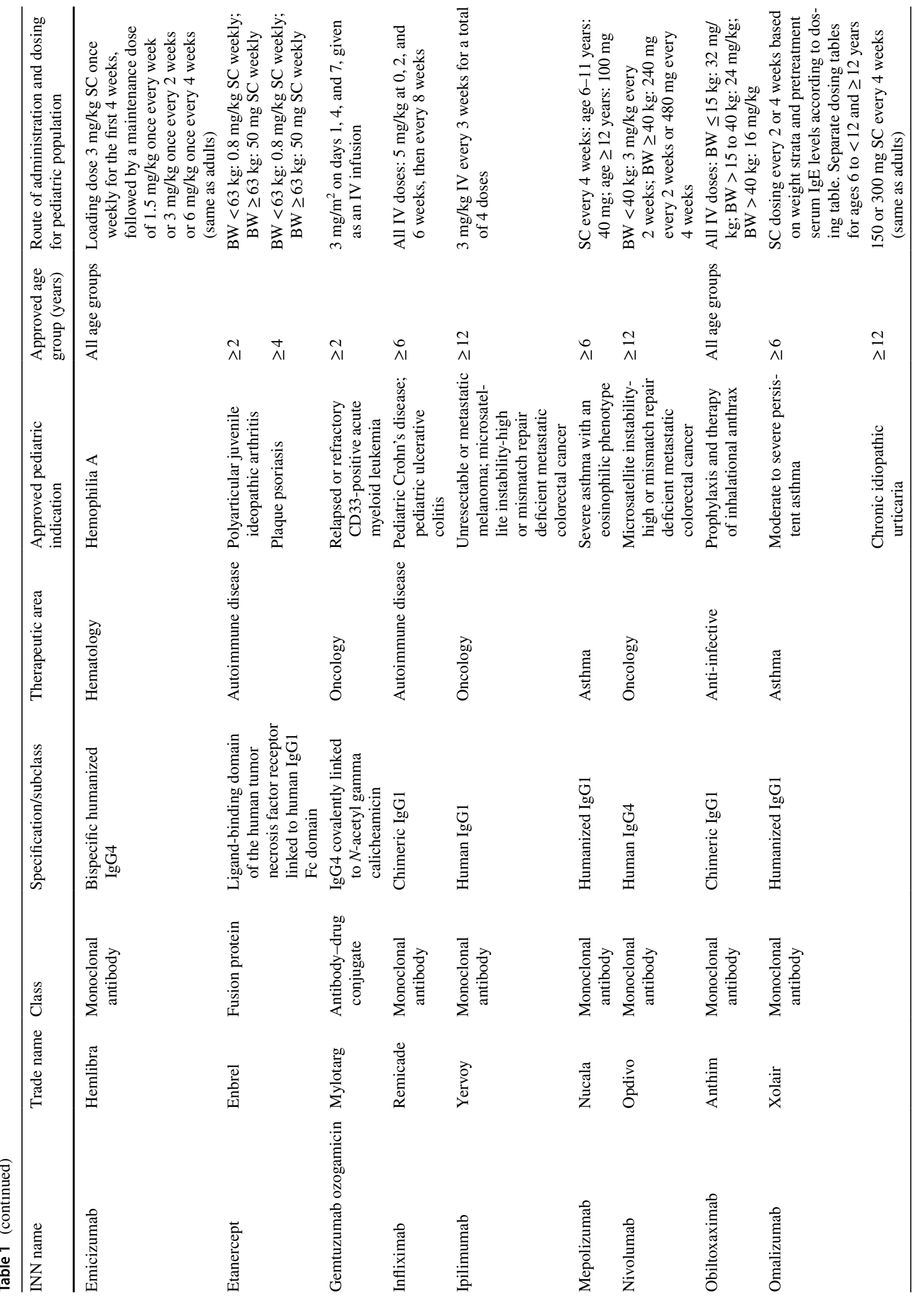




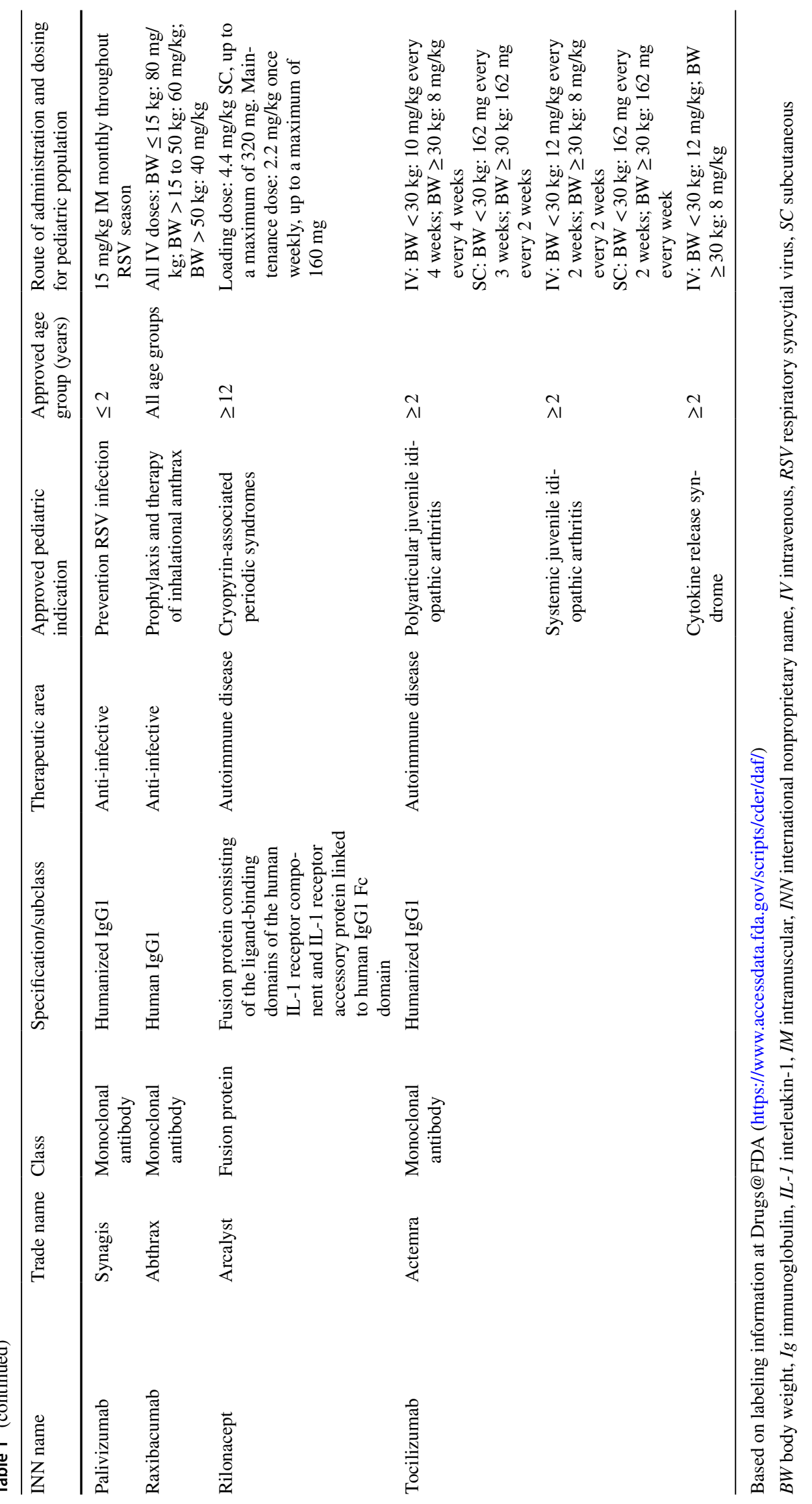




\subsubsection{Tiered Fixed Dosing}

Tiered fixed dosing uses one or several body weight or age cutoffs to define patient strata that receive different flat doses. It allows clinicians to account for different dosing needs based on body weight and/or age, and is highly attractive due to its simplicity of implementation. Since most mAb-based therapeutics have relatively good tolerability, a certain limited variability in drug exposure may be acceptable [3], making tiered fixed dosing a viable option despite its theoretically lower dosing precision relative to allometric or body weight-adjusted dosing. To define adequate weight and/or age cutoffs, prior PK data in the covered age group and pharmacometric analyses are usually needed to derive optimal strata sizes through model-based simulations.

\subsubsection{Tiered Body Weight-Based Dosing}

Tiered body weight-based dosing is probably currently the most widely applied dosing strategy for mAbs in children. This approach uses one or several body weight or age cutoffs to define patient strata that receive different body weight-adjusted doses. It allows more individualized dosing than the tiered fixed dosing approach, but still seems very well accepted and manageable in clinical settings. Similar to tiered fixed dosing, weight and/or age strata cutoffs are usually developed based on prior PK data in the covered age groups and model-based pharmacometric simulation exercises.

\subsubsection{Hybrid Approaches}

Hybrid approaches of tiered fixed dosing and body weightbased dosing have also successfully been applied, where patients above a certain body weight cutoff receive a flat fixed dose, while those below receive a body weightadjusted dose. This approach seems particularly attractive for mAbs with flat dosing in the adult population but need dose adjustments below a certain age range.

\subsubsection{PD Endpoint Approaches}

PD endpoint approaches have so far only been utilized in rare instances, but can be useful if TMDD affects the disposition of the $\mathrm{mAb}$ and the $\mathrm{mAb}$ target is easily accessible for quantification. This is, for example, the case for omalizumab, where the dosing strategy in children with allergic asthma is based on the patient's body weight and the baseline level for endogenous IgE, the pharmacologic target of omalizumab [55].

\section{Specific Examples}

In the following sections, two specific mAb products, abatacept and tocilizumab, are discussed in more detail to highlight clinical pharmacologic differences between pediatric and adult patients. The selected examples represent biological drugs that are approved for both adult and pediatric indications, but have different structural forms: abatacept is a fusion protein with a molecular weight of $92 \mathrm{kDa}$, and tocilizumab is a humanized $\mathrm{mAb}$ with a molecular weight of $148 \mathrm{kDa}$.

\subsection{Abatacept}

Abatacept (Orencia ${ }^{\circledR}$ ), a selective costimulation modulator, is a soluble fusion protein that consists of the extracellular domain of human cytotoxic T-lymphocyte-associated antigen 4 (CTLA-4) linked to the modified Fc (hinge, $\mathrm{CH} 2$, and $\mathrm{CH} 3$ domains) portion of IgG1. Abatacept inhibits T-cell activation by binding to $\mathrm{CD} 80$ and $\mathrm{CD} 86$, thereby blocking interaction with CD28. This interaction provides a costimulatory signal necessary for full activation of $\mathrm{T}$ lymphocytes. Activated $\mathrm{T}$ lymphocytes are implicated in the pathogenesis of rheumatoid arthritis (RA) and psoriatic arthritis (PsA), and are found in the synovium of patients with RA and PsA.

IV and SC administration of abatacept is approved for adult RA and adult PsA. In pediatric patients, abatacept is approved for the treatment of polyarticular juvenile idiopathic arthritis (pJIA) in individuals 6 years of age or older using IV administration and in those 2 years of age or older using SC administration. In this example, we compare the clinical pharmacology of abatacept between pediatric pJIA and adult RA patients.

\subsubsection{Pediatric Development Considerations}

Abatacept was first evaluated in adult RA patients. This development program provided the critical clinical experience, in terms of safety and efficacy, for a first-in-class agent using a novel mechanism of action [56, 57].

The various subtypes of JIA present clinical, histologic, and immunologic similarities, but also differences when compared to adult RA. The pharmaceutical interventions to treat pJIA are similar to those in adult RA, including antitumor necrosis factor (anti-TNF) therapies. T cells play a pivotal role in the immunopathogenesis of both pJIA and adult RA, largely because the production of many inflammatory mediators is under T-cell control. Considering these factors, abatacept's safety and efficacy in pJIA children (6-17 years old) was first studied in a phase 3 study at a dose level of $10 \mathrm{mg} / \mathrm{kg}$. The rationale for the dose used in children was based on similar considerations to those taken 
into account in adults. As abatacept is a biologic, exposure in adults and children after body weight-based dosing is expected to be similar but slightly lower in children relative to adults based on the nonlinear relationship between body weight and $\mathrm{mAb}$ clearance, as discussed earlier. Given the relatively flat exposure-response curve established in adult RA, however, it was assumed that slightly lower exposure in children would not have a substantially negative effect on the efficacy in this population.

The pJIA indication was later extended to children aged 2 years or older for $\mathrm{SC}$ administration of abatacept. Based on the therapeutic equivalence of the formulations (IV and SC) in adult RA, and the similarities between disease state (RA and pJIA), an extrapolation approach was considered suitable to characterize the clinical profile of SC abatacept in pJIA. The extrapolation plan included combined SC and IV population PK and exposure-response modeling to support dosing recommendations for $\mathrm{SC}$ abatacept in pJIA patients aged 2-17 years old and the performance of a PK study to confirm SC doses of abatacept in pJIA patients aged 2-17 years old. The corresponding clinical study, IM101301, was conducted to address the remaining gaps in knowledge, with PK as the primary endpoint. Efficacy and safety were also evaluated to confirm that the benefit-risk profile was comparable to that observed with IV abatacept in pJIA [58]. In this study, body weight-tiered SC dosing was selected to maintain or exceed the exposure level $(\geq 10 \mu \mathrm{g} / \mathrm{mL})$ shown to be associated with efficacy in adults. Body weight-based dosing assumes a linear relationship between dose and body weight, but the relationship between body weight and clearance is often nonlinear for many biologics. This results in slightly lower exposure in low-body-weight patients after body weight-based dosing. The body weight-tiered dosing strategy minimizes the risk of low exposure by adjusting the dose with different body weight tiers. A PK evaluation in this study showed that comparable trough concentrations were achieved across the body weight tiers that exceeded the target concentration. The exposure-response relationship for the efficacy endpoint was developed using two phase 3 studies in pJIA patients. The exposure-response analyses demonstrated that weight-tiered SC dosing provides near maximal efficacy by achieving target exposure and therapeutic efficacy comparable to the IV regimen in pJIA patients. The resulting approved dosing recommendation for abatacept used in children aged $\geq 2$ years with moderately to severely active pJIA is a tiered dosing approach with three weight-based dosing groups: body weight 10 to $<25 \mathrm{~kg}$ : $50 \mathrm{mg} /$ week; body weight 25 to $<50 \mathrm{~kg}: 87.5 \mathrm{mg}$ / week; body weight $\geq 50 \mathrm{~kg}: 125 \mathrm{mg} /$ week [59].

\subsubsection{PK/PD and Immunogenicity}

3.1.2.1 Absorption Abatacept SC injection is the preferable route of administration and is currently approved for multiple indications. Abatacept is slowly absorbed after SC injection, with an absorption half-life of $\sim 3.2$ days in pediatric patients compared to $\sim 9.5$ days in adults $[58,60]$. SC absorption of therapeutic proteins is usually prolonged as lymph fluid drains slowly into the vascular system. The time to reach peak systemic concentrations following SC administration usually ranges from 2 to 8 days after administration $[7,61]$. The SC bioavailability of abatacept was $\sim 92 \%$ in pediatric pJIA patients compared to $\sim 80 \%$ in adult RA patients $[58,60]$. The less than $100 \%$ bioavailability following SC administration is expected due to potential catabolism by macrophages and monocytes at the administration site and/or during the circulation through the lymphatic system.

3.1.2.2 Distribution The model-estimated total volume of distribution at steady state for abatacept is $7.4 \mathrm{~L}$ (5th-95th confidence interval [CI] 4.4-9.8) for pediatric pJIA patients with a body weight of $70 \mathrm{~kg}$ (5th-95th CI 32-108) and 7.5 L (5th-95th CI 6.2-7.6) for adult RA subjects with a body weight of $70 \mathrm{~kg}$ (5th-95th CI 49-110) [58,60]. The volume of distribution of abatacept is expected to be greater in patients with higher body weight because of the increase in extracellular space available for distribution, as has been described for mAbs and other therapeutic proteins [62]. Age is not a significant predictor of volume of distribution of abatacept. Thus, the distribution of abatacept is not significantly affected by developmental changes in body composition across the studied age range. However, distribution may be influenced by binding to plasma proteins or tissue target. Abatacept binds to CD80 and CD86 on antigen-presenting cells present in the systemic circulation as well as various tissues. The observed linear PK profiles of abatacept in adults and children, however, indicate that the molar concentrations of abatacept at therapeutic doses are multifold higher than the molar concentrations of its targeted antigens. Therefore, any potential difference in target expression between adults and children does likely not play a major role in differences in the distribution of abatacept.

3.1.2.3 Metabolism and Elimination Similar to other therapeutic proteins, abatacept is metabolized by catabolic pathways and broken down into small peptides and amino acids through proteolysis. Proteolytic enzymes such as proteases and peptidases are ubiquitously available throughout the body [63]. Abatacept PK after SC administration was best described using a first-order absorption and first-order elimination process. Based on the linear PK observed across the dose range, it appears that abatacept is primarily eliminated through non-specific catabolism, the common elimination pathway that is shared by endogenous IgG and therapeutic mAbs. Abatacept linear clearance has been estimated to be $0.02 \mathrm{~L} / \mathrm{h}$ in pediatric pJIA patients, which is similar to 
the $0.0204 \mathrm{~L} / \mathrm{h}$ reported in adult RA patients. The terminal half-life of abatacept was $\sim 14$ days [58-60]. Since children, including infants, are able to maintain the homeostasis of immunoglobulins, they are presumably able to effectively "metabolize" therapeutic mAbs if unspecific catabolism is the major pathway for the clearance of the mAb. Consequently, no age-related developmental differences were expected for abatacept. Abatacept clearance increased with body weight, glomerular filtration rate, and swollen joint count; decreased with age and albumin levels; was lower in females than males; and was higher in patients treated with concomitant nonsteroidal anti-inflammatory drugs. Among these covariate effects, only the body weight effect was interpreted as clinically relevant $[58,60]$.

3.1.2.4 Immunogenicity ADA to abatacept were detected in $1-2 \%$ of adult RA patients, independent of the route of administration. However, results in pJIA patients were $13-41 \%$, substantially higher than those seen in adult RA patients treated with abatacept [59]. The presence of ADA was generally transient and titers were low, and it was not associated with adverse events, changes in efficacy, or an effect on serum concentrations of abatacept.

\subsection{Tocilizumab}

Tocilizumab (Actemra ${ }^{\circledR}$ ) is a recombinant humanized $\mathrm{mAb}$ of the IgG1 subclass directed against the soluble and membrane-bound interleukin-6 receptor (IL-6R). Interleukin-6 is a multifunctional cytokine that regulates immune responses and inflammatory reactions, and is likely to mediate the autoimmune, inflammatory, and joint destruction aspects of RA. IV and SC administration of tocilizumab is approved in adult patients for the treatment of RA after an inadequate response to TNF antagonist therapies and for treatment of giant cell arteritis. In pediatrics, tocilizumab is indicated for the treatment of systemic onset juvenile idiopathic arthritis (sJIA), pJIA, and chimeric antigen receptor (CAR) T-cellinduced severe or life-threatening cytokine release syndrome in patients aged 2 years or older. In this example, we limit our review to the comparison of the clinical pharmacology of tocilizumab in adult RA patients and pediatric patients with sJIA.

\subsubsection{Pediatric Development Considerations}

Similar to its development in adult patients, tocilizumab's development in the pediatric population started with an IV regimen. The clinical development plan for pediatric sJIA patients included phase $1 \mathrm{~b}$ studies to assess PK, PD, safety, and efficacy at different doses and dosing regimens. This was followed by a pivotal phase 3 study to confirm its efficacy and safety. The subsequent phase 1b study WA28118 was a PK/PD bridging study to bridge the proposed tocilizumab SC regimen to the approved tocilizumab IV regimens for sJIA, based on PK extrapolation. The study aimed to identify the SC regimens that achieve comparable PK/PD and safety profiles relative to the IV regimens established in study WA18221. The proposed SC dose regimen was based on the population PK model developed for sJIA with an IV formulation (study WA18221), and assuming similar $\mathrm{SC}$ absorption as in the adult RA population. The PK profiles for different SC dose regimens were then simulated for sJIA patients to maintain exposure levels above the target steady-state trough concentration $\left(C_{\min }\right)$ achieved with the tocilizumab IV regimen. $C_{\min }$ was considered the primary PK metric predictive of efficacy. Similar to several other $\mathrm{mAbs}$, tocilizumab clearance increases with an increase in body weight. Thus, flat dose administration often results in lower exposure in higher-body-weight patients compared to lower-body-weight patients. The body weight-tiered dosing regimen adjustment from once every 2 weeks to once a week minimizes the risk of lower exposure for patients $\geq 30 \mathrm{~kg}$. The resulting FDA-approved dosing regimen for tocilizumab in children with sJIA aged 2-17 years is a tiered dosing approach, with an SC dose of $162 \mathrm{mg}$ every 2 weeks for individuals whose body weight is $<30 \mathrm{~kg}$ and an SC dose of $162 \mathrm{mg}$ every week for patients $\geq 30 \mathrm{~kg}$ [64].

\subsubsection{PK/PD and Immunogenicity}

3.2.2.1 Absorption After SC administration, tocilizumab is absorbed from the SC tissue into the systemic circulation, resulting in lower bioavailability and a lower and later peak plasma concentration compared with IV administration. The absorption half-life after SC administration is 1.7 days in pediatric patients compared to $\sim 3$ days in adults. The absolute bioavailability is approximately $\sim 95 \%$ in pediatric patients with sJIA compared to $80 \%$ in adult patients with RA [64, 65]. The relatively smaller thickness of SC tissue and higher perfusion rate and increased lymphatic flow in children may play a role in the faster absorption and higher bioavailability of tocilizumab in pediatric compared to adult patients.

3.2.2.2 Distribution Following SC administration, the estimated population average volume of distribution at steady state was $4 \mathrm{~L}$ [including $1.87 \mathrm{~L}$ of central volume of distribution $\left(V_{\mathrm{c}}\right)$ and $2.14 \mathrm{~L}$ of peripheral volume of distribution $\left(V_{\mathrm{p}}\right)$ ] for a reference sJIA pediatric patient with a body weight of $\sim 37 \mathrm{~kg}$ (calculated using reported reference population mean body mass index (BMI) and height) and $7.3 \mathrm{~L}$ (including $4.5 \mathrm{~L}$ of $V_{\mathrm{c}}$ and $2.8 \mathrm{~L}$ of $V_{\mathrm{p}}$ ) for a reference adult subject of $70 \mathrm{~kg}$. The volume of distribution of tocilizumab is expected to be proportionately higher in patients with higher body weight, because of the larger extracellular 
space available for tocilizumab distribution. The allometric coefficient for the effect of body size on volume of distribution was estimated as 1.1 using BSA in pediatric sJIA patients and 0.68 for body weight in adult RA patients. The different measures of body size, including BSA, body weight, and BMI, are highly correlated, and their effect on $\mathrm{mAb} \mathrm{PK}$ is expected to show some similarity. The large central volume of distribution relative to total plasma volume suggests that tocilizumab distribution is confined to plasma and extracellular fluid. As tocilizumab binds to its target, soluble and membrane-standing IL-6R, its circulatory levels have shown correlations with both disease activity and the extent and severity of joint involvement [66].

3.2.2.3 Metabolism and Elimination Tocilizumab is expected to be metabolized by the same catabolic pathways as endogenous $\operatorname{IgG}$ molecules. Proteolytic degradation at the site of injection or during transport through the lymphatic system results in less than $100 \%$ bioavailability after SC administration. Tocilizumab PK after SC administration at therapeutic doses were best described using parallel linear and nonlinear clearance and a first-order absorption process. The clearance of tocilizumab is concentration dependent and decreases with increasing dose. As a result, the terminal half-life of tocilizumab also increases with increasing dose. The median effective half-life of tocilizumab during a dosing interval at steady-state varies between 12.2 and 13.5 days for the 162-mg once a week regimen in patients weighing $\geq 30 \mathrm{~kg}$ [67]. For patients weighing $<30 \mathrm{~kg}$, the median effective half-life of tocilizumab during a dosing interval at steady state varies between 10.7 and 13.9 days for the 162-mg once every 2 weeks regimen. Tocilizumab linear clearance has been estimated as $0.150 \mathrm{~L} /$ day in pediatric sJIA patients compared to $0.216 \mathrm{~L}$ /day in adult RA patients [65, 67]. Similarly, tocilizumab's nonlinear clearance is characterized by a model-estimated maximum target-mediated elimination rate $\left(V_{\max }\right)$ and Michaelis-Menten constant $\left(K_{\mathrm{m}}\right)$ of $5.81 \mathrm{mg} / \mathrm{L} /$ day and $0.462 \mu \mathrm{g} / \mathrm{mL}$, respectively, in pediatric sJIA patients compared to $1.9 \mathrm{mg} / \mathrm{L} /$ day and $0.34 \mu \mathrm{g} / \mathrm{mL}$, respectively, in adult RA patients. Body size is the most influential covariate for tocilizumab clearance in both pediatric and adult patients. The allometric coefficient for the effect of body weight on clearance was 0.51 in adult RA patients. The allometric coefficient of 1.1 for the effect of body size on clearance in pediatric sJIA was estimated as a combined effect including other parameters, such as $V_{\mathrm{c}}, V_{\mathrm{p}}$, and $V_{\max }$. Hence, the direct comparison of the effect of body weight on clearance between adult and pediatric patients is not possible.

3.2.2.4 Immunogenicity The overall immunogenicity rate with SC tocilizumab was low and comparable in adults and pediatric patients. ADA to tocilizumab after SC adminis- tration were detected in $0.8-1.6 \%$ of individuals. The ADA had no impact on the PK, safety, or efficacy of tocilizumab. In sJIA, no patients were found to be ADA positive at postbaseline assessments after SC administration [65, 67].

\section{Conclusions}

With an increasing number of mAbs being approved for pediatric indications, there is a growing knowledgebase on the PK and clinical pharmacology of this class of compounds in pediatric patient populations of different ages. Based on the clinical experiences and theoretical considerations, there are a variety of different drug disposition mechanisms that may be affected by age and thus can result in differences in the PK and PK/PD behavior of $\mathrm{mAbs}$ in children compared to adults. While these age-based differences can to a large degree be addressed by body size-based dosing, especially by adequately considering the nonlinear relationship between clearance and body size according to allometric principles, additional age-related dose adjustments may be necessary in younger pediatric populations such as neonates and infants. As the available data and mechanistic understanding of relevant drug disposition processes, as well as the clinical experience with $\mathrm{mAbs}$ in pediatric populations, are still evolving, PK predictions and dosing regimen development for novel $\mathrm{mAbs}$ in pediatric patient groups still involve substantial uncertainties that hamper a more streamlined drug-development process for mAbs in pediatric indications. A more mechanistic understanding is urgently needed regarding (1) the molecular and physiologic processes relevant for $\mathrm{mAb}$ disposition, especially when TMDD processes are involved, and (2) the modulation of these processes through childhood development and patient-specific maturational trajectories. In addition, an improved understanding of immunogenicity and its modulation of $\mathrm{mAb}$ clinical pharmacology in children seems highly desirable, but remains challenging as participant numbers in most pediatric studies are much lower than in comparable adult clinical trials, and thus reliable assessment of relatively infrequent immunogenicity events is particularly difficult.

Acknowledgements Open access was funded by the University of Tennessee Health Science Center.

\section{Compliance with Ethical Standards}

Funding No funding has been received in support of the writing of this article.

Conflict of interest ZHT and BM have no conflicts of interest to declare. SS is an employee of Bristol-Myers Squibb Company. 
Open Access This article is licensed under a Creative Commons Attribution-NonCommercial 4.0 International License, which permits any non-commercial use, sharing, adaptation, distribution and reproduction in any medium or format, as long as you give appropriate credit to the original author(s) and the source, provide a link to the Creative Commons licence, and indicate if changes were made. The images or other third party material in this article are included in the article's Creative Commons licence, unless indicated otherwise in a credit line to the material. If material is not included in the article's Creative Commons licence and your intended use is not permitted by statutory regulation or exceeds the permitted use, you will need to obtain permission directly from the copyright holder.To view a copy of this licence, visit $\mathrm{http} / / /$ creativecommons.org/licenses/by-nc/4.0/.

\section{References}

1. Ryman JT, Meibohm B. Pharmacokinetics of monoclonal antibodies. CPT Pharmacomet Syst Pharmacol. 2017;6(9):576-88. https ://doi.org/10.1002/psp4.12224.

2. Mould DR, Meibohm B. Drug development of therapeutic monoclonal antibodies. BioDrugs. 2016;30(4):275-93. https://doi. org/10.1007/s40259-016-0181-6.

3. Xu Z, Davis HM, Zhou H. Rational development and utilization of antibody-based therapeutic proteins in pediatrics. Pharmacol Ther. 2013;137(2):225-47. https://doi.org/10.1016/j.pharmthera .2012.10.005.

4. Anderson BJ, Holford NH. Mechanism-based concepts of size and maturity in pharmacokinetics. Annu Rev Pharmacol Toxicol. 2008;48:303-32. https://doi.org/10.1146/annurev.pharm tox.48.113006.094708.

5. Meibohm B, Laer S, Panetta JC, Barrett JS. Population pharmacokinetic studies in pediatrics: issues in design and analysis. AAPS J. 2005;7(2):E475-87. https://doi.org/10.1208/aapsj07024 8.

6. Meibohm B. Pharmacokinetics and pharmacodynamics of therapeutic peptides and proteins. In: Crommelin DJA, Sindelar RD, Meibohm B, editors. Pharmaceutical biotechnology: fundamentals and applications. 5th ed. Springer: New York; 2019. p. 105-37.

7. Dirks NL, Meibohm B. Population pharmacokinetics of therapeutic monoclonal antibodies. Clin Pharmacokinet. 2010;49(10):63359. https://doi.org/10.2165/11535960-000000000-00000.

8. Kingwell K. Drug delivery: new targets for drug delivery across the BBB. Nat Rev Drug Discov. 2016;15(2):84-5. https://doi. org/10.1038/nrd.2016.14.

9. Baxter LT, Zhu H, Mackensen DG, Jain RK. Physiologically based pharmacokinetic model for specific and nonspecific monoclonal antibodies and fragments in normal tissues and human tumor xenografts in nude mice. Cancer Res. 1994;54(6):1517-28.

10. Flessner MF, Lofthouse J, el Zakaria R. In vivo diffusion of immunoglobulin $\mathrm{G}$ in muscle: effects of binding, solute exclusion, and lymphatic removal. Am J Physiol. 1997;273(6 Pt 2):H2783-93.

11. Bell DR, Watson PD, Renkin EM. Exclusion of plasma proteins in interstitium of tissues from the dog hind paw. Am J Physiol. 1980;239(4):H532-8.

12. Malik P, Edginton A. Pediatric physiology in relation to the pharmacokinetics of monoclonal antibodies. Expert Opin Drug Metab Toxicol. 2018;14(6):585-99. https://doi.org/10.1080/17425 255.2018.1482278.

13. Friis-Hansen B. Water distribution in the foetus and newborn infant. Acta Paediatr Scand Suppl. 1983;305:7-11.

14. Kearns GL, Abdel-Rahman SM, Alander SW, Blowey DL, Leeder JS, Kauffman RE. Developmental pharmacology—drug disposition, action, and therapy in infants and children. N Engl J Med. 2003;349(12):1157-67. https://doi.org/10.1056/NEJMra035092.
15. Schaefer B, Bartosova M, Macher-Goeppinger S, Ujszaszi A, Wallwiener M, Nyarangi-Dix J, et al. Quantitative histomorphometry of the healthy peritoneum. Sci Rep. 2016;6:21344. https:// doi.org/10.1038/srep21344.

16. Malik PRV, Hamadeh A, Phipps C, Edginton AN. Population PBPK modelling of trastuzumab: a framework for quantifying and predicting inter-individual variability. J Pharmacokinet Pharmacodyn. 2017;44(3):277-90. https://doi.org/10.1007/s1092 8-017-9515-3.

17. Limothai W, Meibohm B. Effect of developmental growth and FcRn expression on the pharmacokinetics of monoclonal antibodies in mice. In: World conference on pharmacometrics, August 21-24, Brisbane; 2016.

18. Waldmann TA, Strober W. Metabolism of immunoglobulins. Prog Allergy. 1969;13:1-110.

19. Berdeja J, Jagannath S, Zonder J, Badros A, Kaufman JL, Manges $\mathrm{R}$, et al. Pharmacokinetics and safety of elotuzumab combined with lenalidomide and dexamethasone in patients with multiple myeloma and various levels of renal impairment: results of a phase Ib study. Clin Lymphoma Myeloma Leuk. 2016;16(3):129_ 38. https://doi.org/10.1016/j.clml.2015.12.007.

20. Wright A, Sato Y, Okada T, Chang K, Endo T, Morrison S. In vivo trafficking and catabolism of $\mathrm{IgG} 1$ antibodies with $\mathrm{Fc}$ associated carbohydrates of differing structure. Glycobiology. 2000;10(12):1347-55.

21. Gessner JE, Heiken H, Tamm A, Schmidt RE. The IgG Fc receptor family. Ann Hematol. 1998;76(6):231-48.

22. Abuqayyas L, Balthasar JP. Application of knockout mouse models to investigate the influence of FcgammaR on the tissue distribution and elimination of $8 \mathrm{C} 2$, a murine $\mathrm{IgG} 1$ monoclonal antibody. Int J Pharm. 2012;439(1-2):8-16. https://doi.org/10.1016/j. ijpharm.2012.09.042.

23. Gibiansky L, Passey C, Roy A, Bello A, Gupta M. Model-based pharmacokinetic analysis of elotuzumab in patients with relapsed/ refractory multiple myeloma. J Pharmacokinet Pharmacodyn. 2016;43(3):243-57. https://doi.org/10.1007/s10928-016-9469-x.

24. Roopenian DC, Akilesh S. FcRn: the neonatal Fc receptor comes of age. Nat Rev Immunol. 2007;7(9):715-25.

25. Tian Z, Sutton BJ, Zhang X. Distribution of rat neonatal Fc receptor in the principal organs of neonatal and pubertal rats. J Recept Signal Transduct Res. 2014;34(2):137-42. https://doi. org/10.3109/10799893.2013.865745.

26. Plebani A, Ugazio AG, Avanzini MA, Massimi P, Zonta L, Monafo V, et al. Serum IgG subclass concentrations in healthy subjects at different age: age normal percentile charts. Eur J Pediatr. 1989;149(3):164-7. https://doi.org/10.1007/bf01958271.

27. Morell A, Terry WD, Waldmann TA. Metabolic properties of IgG subclasses in man. J Clin Investig. 1970;49(4):673-80. https://doi. org/10.1172/JCI106279.

28. Beaufrere B. Protein turnover in low-birth-weight (LBW) infants. Acta Paediatr Suppl. 1994;405:86-92.

29. Maeda M, van Schie RC, Yuksel B, Greenough A, Fanger MW, Guyre PM, et al. Differential expression of Fc receptors for IgG by monocytes and granulocytes from neonates and adults. Clin Exp Immunol. 1996;103(2):343-7. https://doi. org/10.1046/j.1365-2249.1996.d01-615.x.

30. Levy G. Pharmacologic target-mediated drug disposition. Clin Pharmacol Ther. 1994;56(3):248-52.

31. Sutjandra L, Rodriguez RD, Doshi S, Ma M, Peterson MC, Jang GR, et al. Population pharmacokinetic meta-analysis of denosumab in healthy subjects and postmenopausal women with osteopenia or osteoporosis. Clin Pharmacokinet. 2011;50(12):793-807. https://doi.org/10.2165/11594240-000000000-00000.

32. Porter CJ, Charman SA. Lymphatic transport of proteins after subcutaneous administration. J Pharm Sci. 2000;89(3):297-310. 
https://doi.org/10.1002/(SICI)1520-6017(200003)89:3\%3c297 :AID-JPS2\%3e3.0.CO;2-P.

33. Shah DK, Betts AM. Towards a platform PBPK model to characterize the plasma and tissue disposition of monoclonal antibodies in preclinical species and human. J Pharmacokinet Pharmacodyn. 2012;39(1):67-86. https://doi.org/10.1007/s10928-011-9232-2.

34. Zhao L, Ji P, Li Z, Roy P, Sahajwalla CG. The antibody drug absorption following subcutaneous or intramuscular administration and its mathematical description by coupling physiologically based absorption process with the conventional compartment pharmacokinetic model. J Clin Pharmacol. 2013;53(3):314-25. https://doi.org/10.1002/jcph.4.

35. Richter WF, Bhansali SG, Morris ME. Mechanistic determinants of biotherapeutics absorption following SC administration. AAPS J. 2012;14(3):559-70. https://doi.org/10.1208/s1224 8-012-9367-0.

36. Olszewski W, Engeset A, Jaeger PM, Sokolowski J, Theodorsen L. Flow and composition of leg lymph in normal men during venous stasis, muscular activity and local hyperthermia. Acta Physiol Scand. 1977;99(2):149-55. https://doi. org/10.1111/j.1748-1716.1977.tb10365.x.

37. Chow TW, Wright MR, Hop C, Wong H. Evaluation of the predictive performance of physiologically based pharmacokinetic models for intramuscular injections of therapeutic proteins. Xenobiotica. 2019. https://doi.org/10.1080/00498254.2019.1571651.

38. Richter WF, Jacobsen B. Subcutaneous absorption of biotherapeutics: knowns and unknowns. Drug Metab Dispos. 2014;42(11):1881-9. https://doi.org/10.1124/dmd.114.059238.

39. Robbie GJ, Zhao L, Mondick J, Losonsky G, Roskos LK. Population pharmacokinetics of palivizumab, a humanized anti-respiratory syncytial virus monoclonal antibody, in adults and children. Antimicrob Agents Chemother. 2012;56(9):4927-36. https://doi. org/10.1128/AAC.06446-11.

40. Chirmule N, Jawa V, Meibohm B. Immunogenicity to therapeutic proteins: impact on PK/PD and efficacy. AAPS J. 2012;14(2):296302. https://doi.org/10.1208/s12248-012-9340-y.

41. Schellekens H. Immunogenicity of therapeutic proteins: clinical implications and future prospects. Clin Ther. 2002;24(11):1720-40.

42. Emi Aikawa N, de Carvalho JF, Artur Almeida Silva C, Bonfa E. Immunogenicity of anti-TNF-alpha agents in autoimmune diseases. Clin Rev Allergy Immunol. 2010;38(2-3):82-9. https://doi. org/10.1007/s12016-009-8140-3.

43. Gunn GR 3rd, Sealey DC, Jamali F, Meibohm B, Ghosh S, Shankar G. From the bench to clinical practice: understanding the challenges and uncertainties in immunogenicity testing for biopharmaceuticals. Clin Exp Immunol. 2016;184(2):137-46. https://doi.org/10.1111/cei.12742.

44. Shakhnovich V, Meibohm B, Rosenberg A, Kierzek AM, Hasenkamp R, Funk RS, et al. Immunogenicity in clinical practice and drug development: when is it significant? Clin Transl Sci. 2019. https://doi.org/10.1111/cts.12717.

45. Simon AK, Hollander GA, McMichael A. Evolution of the immune system in humans from infancy to old age. Proc Biol Sci. 1821;2015(282):20143085. https://doi.org/10.1098/ rspb.2014.3085.

46. Ygberg S, Nilsson A. The developing immune system-from foetus to toddler. Acta Paediatr. 2012;101(2):120-7. https://doi.org/ 10.1111/j.1651-2227.2011.02494.x.

47. Tulic MK, Andrews D, Crook ML, Charles A, Tourigny MR, Moqbel R, et al. Changes in thymic regulatory T-cell maturation from birth to puberty: differences in atopic children. J Allergy Clin Immunol. 2012;129(1):199-206.e1-4. https://doi.org/10.1016/j. jaci.2011.10.016.
48. Wilson $\mathrm{CB}$. The ontogeny of T lymphocyte maturation and function. J Pediatr. 1991;118(3):S4-9. https://doi.org/10.1016/s0022 $-3476(05) 82182-1$.

49. Basha S, Surendran N, Pichichero M. Immune responses in neonates. Expert Rev Clin Immunol. 2014;10(9):1171-84. https://doi. org/10.1586/1744666X.2014.942288.

50. Doeleman MJH, van Maarseveen EM, Swart JF. Immunogenicity of biologic agents in juvenile idiopathic arthritis: a systematic review and meta-analysis. Rheumatology (Oxford). 2019;58(10):1839-49. https://doi.org/10.1093/rheumatology/ kez030.

51. Mehrotra N, Bhattaram A, Earp JC, Florian J, Krudys K, Lee JE, et al. Role of quantitative clinical pharmacology in pediatric approval and labeling. Drug Metab Dispos. 2016;44(7):924-33. https://doi.org/10.1124/dmd.116.069559.

52. Xu Y, Adedokun OJ, Chan D, Hu C, Xu Z, Strauss RS, et al. Population pharmacokinetics and exposure-response modeling analyses of golimumab in children with moderately to severely active ulcerative colitis. J Clin Pharmacol. 2019;59(4):590-604. https://doi.org/10.1002/jcph.1353.

53. Gill KL, Gardner I, Li L, Jamei M. A bottom-up whole-body physiologically based pharmacokinetic model to mechanistically predict tissue distribution and the rate of subcutaneous absorption of therapeutic proteins. AAPS J. 2016;18(1):156-70. https://doi. org/10.1208/s12248-015-9819-4.

54. Malik PRV, Edginton AN. Physiologically-based pharmacokinetic modelling versus allometric scaling for the prediction of infliximab pharmacokinetics in pediatric patients. CPT Pharmacomet Syst Pharmacol. 2019;8(11):835-44. https://doi.org/10.1002/ psp4.12456.

55. Zhang Y, Wei X, Bajaj G, Barrett JS, Meibohm B, Joshi A, et al. Challenges and considerations for development of therapeutic proteins in pediatric patients. J Clin Pharmacol. 2015;55(Suppl 3):S103-15. https://doi.org/10.1002/jcph.382.

56. Roy A, Mould DR, Wang XF, Tay L, Raymond R, Pfister M. Modeling and simulation of abatacept exposure and interleukin-6 response in support of recommended doses for rheumatoid arthritis. J Clin Pharmacol. 2007;47(11):1408-20. https://doi. org/10.1177/0091270007307573.

57. Zhou S, Roy A, Murthy B, et al. Relationship between systemic exposure and efficacy and safety of abatacept administered subcutaneously and intravenously in adult rheumatoid arthritis patients. In: American Association of Pharmaceutical Scientists National Biotechnology Conference, May 16-18, San Francisco, poster W3101; 2011.

58. Li X, Roy A, Murthy B. Population pharmacokinetics and exposure-response relationship of intravenous and subcutaneous abatacept in patients with rheumatoid arthritis. J Clin Pharmacol. 2019;59(2):245-57. https://doi.org/10.1002/jcph.1308.

59. Bristol-Myers Squibb Company. ORENCIA (ABATACEPT) prescribing information. Princeton; 2019.

60. Li X, Passarell JA, Lin KJ, Roy A, Murthy B, Girgis IH. Population pharmacokinetics and exposure-response analyses for abatacept in juvenile idiopathic arthritis. In: American conference on pharmacometrics (ACoP8), October 15-18, Fort Lauderdale; 2017.

61. Xu Z, Wang Q, Zhuang Y, Frederick B, Yan H, Bouman-Thio E, et al. Subcutaneous bioavailability of golimumab at 3 different injection sites in healthy subjects. J Clin Pharmacol. 2010;50(3):276-84. https://doi.org/10.1177/0091270009340782.

62. Kloft C, Graefe EU, Tanswell P, Scott AM, Hofheinz R, Amelsberg A, et al. Population pharmacokinetics of sibrotuzumab, a novel therapeutic monoclonal antibody, in cancer patients. Investig New Drugs. 2004;22(1):39-52.

63. Tabrizi MA, Tseng CM, Roskos LK. Elimination mechanisms of therapeutic monoclonal antibodies. Drug 
Discov Today. 2006;11(1-2):81-8. https://doi.org/10.1016/S1359 $-6446(05) 03638-X$.

64. Genentech Inc. ACTEMRA (Tocilizumab) prescribing information. South San Francisco; 2019.

65. Abdallah H, Hsu JC, Lu P, Fettner S, Zhang X, Douglass W, et al. Pharmacokinetic and pharmacodynamic analysis of subcutaneous tocilizumab in patients with rheumatoid arthritis from 2 randomized, controlled trials: SUMMACTA and BREVACTA. J Clin Pharmacol. 2017;57(4):459-68. https://doi.org/10.1002/jcph.826.
66. Rooney M, David J, Symons J, Di Giovine F, Varsani H, Woo P. Inflammatory cytokine responses in juvenile chronic arthritis. $\mathrm{Br}$ J Rheumatol. 1995;34(5):454-60. https://doi.org/10.1093/rheum atology/34.5.454.

67. European Medicines Agency. Assessment report for tocilizumab type II variation EMEA/H/C/955/II/76 for systemic idiopathic juvenile arthritis. London; 2018. 